\title{
Study of Reproductive Toxicity of the Liposomal Photosensitizer Lipophthalocyan
}

\author{
Authors \\ Olga Konyaeva', Nataliya Kulbachevskaya', Vera Chaley', Nadezhda Ermakova', Pavel Varaksa', Anna Lantsova', \\ Lyudmila Nikolaeva1, 2, Olga Orlova', Yuliya Rodionova', Natalia Bunyatyan², 3
}

\author{
Affiliations \\ 1 N.N. National Medical Research Center of Oncology, \\ Moscow, Russia \\ 2 Sechenov University, Moscow, Russia \\ 3 Scientific Center for Expert Evaluation of Medicinal \\ Products, Ministry of Health of Russia, Moscow, Russia
}

\section{Key words}

embryotoxicity, teratogenicity, preimplantation mortality, post-implantation mortality

received 25.03.2021

accepted 21.06.2021

published online $\quad 29.07 .2021$

Bibliography

Drug Res 2021; 71: 504-511

DOI 10.1055/a-1533-2900

ISSN 2194-9379

(c) 2021. Thieme. All rights reserved.

Georg Thieme Verlag KG, Rüdigerstraße 14,

70469 Stuttgart, Germany

\section{Correspondence}

L. Nikolaeva

N.N. National Medical Research Center of Oncology

Kashirskoe sh., 24

Moscow

115478

Russia

Tel.: + 7-915-296-31-70

alima91@yandex.ru

\section{ABSTRACT}

Objective Study of embryotoxicity, teratogenicity and reproductive toxicity of the new drug Lipophtalocyan in rats.

Material and Methods Studies were conducted on 210 noninbred female rats and 105 non-inbred male rats. The drug was administered daily via i. v. injection for 48 days (males) and for 15 days (females) in 2 total doses corresponding to the therapeutic dose (TD) for mice when converted to rats and 10 TD. Results and Conclusion When mating with intact female rats, no changes in sexual behavior were observed, but the index of the ability to fertilize and conceive decreased when compared to the values of the control group by $35-40 \%$ (TD index $=60 \%$ ) and by $75-80 \%$ ( 10 TD index $=20 \%$ ). The index of the ability to fertilize and conceive differed from the values of the control group by $90 \%$ (TD index $=5 \%$ ) and by $15 \%$ ( 10 TD index $=80 \%$ ). There were no differences in the indicator of embryotoxicity and teratogenicity in intact and drug-treated female rats, compared with the control group. Lipophtalocyan has a negative effect on the male and female reproductive function in rats and has an embryotoxic effect according to the index of the ability to fertilize and conceive, as well as the indices of preimplantation and post-implantation fetal death. The drug does not have a teratogenic effect, neither it affects the physical development of offspring or the rate of maturation of sensory-motor reflexes during feeding.

\section{Introduction}

The search for effective and local forms of anti-cancer therapy that have low systemic toxicity is conducted in multiple directions, where one of them is photodynamic therapy (PDT). PDT has great prospects of application for a number of local skin and mucosal cancers. Along with high antitumor effectiveness, selectivity of exposure and the absence of systemic side effects, PDT provides high physiological safety and a good positive outcome. However, the clinical experience of PDT with drugs based on photosensitizers (PS) has shown that the depth of photodynamic exposure is insufficient for the effective treatment of many common tumors. These
PS have a low tumor accumulation selectivity and cause side effects (in particular, residual skin phototoxicity, edema of the irradiated area after photodynamic exposure, etc.). Thus, it is extremely important and urgent to create a PS with spectral range of absorbtion between $710-740 \mathrm{~nm}$, where the biological tissue absorption is insignificant. PDT using such PS will provide the possibility of effective destruction of the tumor node to a depth of at least $1 \mathrm{~cm} \mathrm{[1].}$

Lipophtalocyan is an original liposomal drug based on a thirdgeneration photosensitizer of tetra-3-phenylthiophthalocyanine aluminum hydroxide with a particle size of about $200 \mathrm{~nm}$. It has a maximum absorption at $717 \pm 4 \mathrm{~nm}$, and provides the possibility of 
intravenous administration of an innovative hydrophobic substance into the patient's body. Development of Lipophtalocyan conducted by a team of researchers from State scientific center "NIOPIK" and N. N. Blokhin National Medical Research Center of Oncology of the Ministry of Health of Russian Federation [2].

In preclinical studies, it was found that Lipophtalocyan has a fairly high selectivity of accumulation in the tumor in relation to normal tissue due to encapsulation of PS in PEG liposomes. The advantages of this drug are high selectivity of exposure to tumor foci, low systemic toxicity, and high efficiency shown in vivo studies [3,4].

Currently, in Russia and abroad, liposomal drug forms of PS are being developed and studied preclinically in order to increase the selectivity of the effect on the tumor and the effectiveness of PDT, but clinical studies have not yet been conducted on any of them $[5,6]$.

All this gives reason to believe that the proposed new liposomal drug Lipophtalocyan can be used in oncology for the treatment of malignant neoplasms. Lipophtalocyan is planned to be used in oncological practice for PDT of neoplasms with superficial and intracavity localization, primarily skin cancer, lower lip, tumors of the oral mucosa and tongue, with intradermal metastases of breast cancer, and later - of the stomach, esophagus, bronchi.

The study of reproductive toxicity of new pharmacological substances is an important part of preclinical toxicological research. The detection of reproductive toxicity of the new drug in animals includes the study of the effect on generative function, as well as the embryonic and fetotoxic effects of the drug, recorded in the antenatal and postnatal periods of development [7-10].

This study deals with embryotoxicity, teratogenicity and reproductive toxicity of Lipophtalocyan in rats.

\section{Materials and Methods}

The research was conducted in accordance with national requirements for the animal care, taking into account methodological recommendations [7-10].

\section{Laboratory animal}

All animal protocols were approved by the Institutional Animal Care and Use Committee at the IBMC. The study was the study was carried out in compliance with the ARRIVE guidelines. The research was conducted on 210 non- inbred female rats and 105 non- inbred male rats weighing 250-300 grams, obtained from an accredited laboratory animal nursery of Krolinfo LLC.

All the animals were healthy and had a veterinary certificate of quality (F2) and health status. Standard industrial certified briquetted rodent feed with a set expiration date was used for animal feeding. Feeding was performed at the same time.

\section{Study medication}

Lipophtalocyan is lyophilizate for the preparation of a solution for injection of $1.5 \mathrm{mg}$, a dry, porous mass of light green color. The drug contains a concentration of the active substance tetra-3-phenylthiophthalocyanine aluminum hydroxide and excipients: phosphatidylcholine E PC S, cholesterol, sucrose, PEG-2000 DSPE.
Before use, the contents of the vial are rehydrated with water for injection to obtain the recommended concentration $0.25 \mathrm{mg} /$ $\mathrm{ml}[3,4]$.

\section{Administration procedure}

To study the reproductive activity of Lipophtalocyan in male rats, the drug was administered daily intravenously for 48 days in 2 doses:

1. total dose of $3.0 \mathrm{mg} / \mathrm{kg}$ (single dose $-0.06 \mathrm{mg} / \mathrm{kg}$ ) the dose corresponding to the therapeutic dose (TD) for mice when converted to rats (TD for mice- $6.0 \mathrm{mg} / \mathrm{kg}$ ),

2. the total dose of $30.0 \mathrm{mg} / \mathrm{kg}$ (single dose $-0.6 \mathrm{mg} / \mathrm{kg}$ ), corresponding to 10 TD (recalculation was performed according to the well-known Freirech method [11]).

To study the reproductive activity of Lipophtalocyan in female rats, the drug was administered daily intravenously 15 times in a fixed concentration of $0.25 \mathrm{mg} / \mathrm{ml}$ in the same total doses (corresponding to TD and 10 TD for mice) as for males (single doses of 0.2 and $2.0 \mathrm{mg} / \mathrm{kg}$, respectively).

Two control groups were used in the study: the first group (both male and female rats) received $i$. v. injection with saline solution of sodium chloride $0.9 \%$ in saline solution in the volumes and at the times corresponding to drug administration to experimental animals. The second control group consisted of intact males and females.

\section{Criteria for evaluating reproductive toxicity}

Each group used 30 female rats and 15 male rats. At the end of the drug administration, female rats were hooked to males in a ratio of 2:1 for a period of two estrous cycles (10 days). Fertilization was recorded using vaginal smears. During the experiment, the condition and behavior of pregnant females were observed.

Pregnant females of control and experimental groups (20 rats from each group) were removed from the experiment by dislocation of the cervical vertebrae on the 20-21 day of pregnancy (the remaining pregnant females (10 rats from each group) were kept until delivery). After opening the abdominal cavity, the uterus was removed and transferred to a Petri dish. After opening the uterus, the number of live, dead, resorbed fetuses and the number of implantation sites were counted. Under binoculars, an external examination of the fetus was performed to detect external abnormalities. The fetus was weighed andthe craniocaudal size $(\mathrm{mm})$ was determined. The number of yellow bodies was counted in the ovaries. Based on these data, we determined the level of pre- and postimplantation fetal mortality, as well as the fertility index $[7,8]$.

Preimplantation death (\%) was determined by the following formula: the ratio between the number of corpus luteum in the ovaries and the number of implantation sites in the uterus divided by the total number of corpus luteum and multiplied by 100 . Post-implantation death (\%) was determined by the formula where the ratio between the number of implantation sites and the number of living fetuses was divided by the total number of implantation sites and multiplied by 100 . To assess the ability to fertilize and conceive, fertility index (\%) was calculated as the ratio between the number of pregnant females snd the number of females and multiplied by 100 . 
For the study of internal organs and the bone system in order to detect abnormalities of fetal development, the fetus was divided into 2 parts. One part was fixed in Bowen's fluid and after fixation was subjected to external examination and examination of internal organs (including the brain) by the Wilson method in the modification of the Department of embryology of the Research Institute of Institute of experimental medicine of Russian Academy of Sciences using thick razor sections at different levels of the head and trunk of the fetus. The other part of the fetuses was fixed in $96 \%$ alcohol. After 10-day fixation, the state of internal organs was examined using the Staples method, which were later removed from the bodies of the embryos. Then the fetuses were processed using the Dawson method, modified by the Department of embryology of the Research Institute of Institute of experimental medicine of Russian Academy of Sciences, with alizarin red color [7, 8] to detect abnormalities in the development of the skeleton.

Fetuses, internal organs and the skeleton were examined using a binocular microscope MBS-9.

The remaining pregnant females (10 rats from each group) were left until delivery and watched the physical development of the offspring until the end of feeding (35 days).

We conducted daily monitoring of the development of the offspring, recorded the general physical condition and behavior, body mass dynamics and death of rat cubs. The assessment included the following recorded indicators of offspring development: litter size, number of live and dead newborns, death of newborns, body weight $(7,14,21,30$ days), peeling of ear (from 2 days), appearance of primary hair (from 4 days), teething of incisors (from 6 days), opening of eyes (from 12 days), ptosis of testes (from 23 days), opening of vagina (from 28 days), flipping on plane (from 2 days), negative geotaxis (from 5 days), avoiding a cliff (from day 9), flipping in free fall (from day 20), open "field test" (day 35).

\section{Statistical analysis}

Statistical processing of the obtained data was performed using the Microsoft Office Excel computer program. Parameters commonly used in toxicology were calculated. For reliable differences were taken at $\mathrm{p} \leq 0.05$.

\section{Results and Discussion}

As a result of studies on the reproductive activity of male rats receiving Lipophtalocyan in total doses corresponding to TD and 10 TD, no clinical manifestations of toxicity and changes in animal behavioral responses were detected within 48 days of administration of the drug. When mating with intact female rats, no changes in sexual behavior were observed in male rats treated with the drug compared to control animals; the emotional state and behavioral responses of male rats did not differ from the behavior of control animal.

When studying the reproductive activity of male rats after the use of Lipophtalocyan in two studied doses, corresponding to TD and 10 TD, when mating with intact females, a dose-dependent negative effect on the generative function of males was revealed. The index of the ability to fertilize and conceive differed from the values of the control groups by $35-40 \%$ (male rats receiving the drug in the TD index $=60 \%$ ) and by $75-80 \%$ (male rats receiving the drug in the 10 TD index $=20 \%)$. The presence of preimplantation fetal death in intact female rats mated with males who received the drug only at a dose of the appropriate TD was established. The percentage of preimplantation fetal death in intact female rats mated with males receiving Lipophtalocyan at a dose of the corresponding TD was $4.3 \%$. Preimplantation fetal death in intact female rats mated with males receiving Lipophtalocyan at a dose corresponding to 10 TD was absent, as in control animals. At the same time, the presence of dose-dependent post-implantation fetal death in intact female rats mated with males who received Lipophtalocyan in the studied doses was established. The percentage of post-implantation fetal death in intact female rats mated with males receiving Lipophtalocyan at a dose corresponding to 10 TD was $16.7 \%$, which was $4.5-6$ times higher than in control animals. The percentage of post-implantation fetal death in intact female rats mated with males receiving Lipophtalocyan at a dose corresponding to TD was $1.8 \%$, which did not differ from the percentage of post-implantation fetal death in control animals (2.7-4.8\%). During external examination of live fetuses, there were no external visible abnormalities of fetus development. Fetus weight and craniocaudal size did not differ from the values of the control groups ( Table 1).

When studying the reproductive activity of female rats during and after administration of the drug in total doses corresponding to TD and 10 TD, no clinical manifestations of toxicity and changes in behavioral responses were detected. Sexual behavior of female rats after the application of Lipophtalocyan did not differ from the behavior of control animals. When dissecting pregnant rats that received the drug, the liver and spleen were stained green in intensity, which depended on the amount of the applied dose of the drug.

When studying the reproductive activity of female rats after the use of Lipophtalocyan in total doses corresponding to TD and 10 TD, when mating with intact males, a negative non-dose-dependent effect on the generative function of females was revealed. The index of the ability to fertilize and conceive differed from the values of the control groups by $90 \%$ (female rats receiving Lipophtalocyan in TD index $=5 \%$ ) and by $15 \%$ (female rats receiving Lipophtalocyan in 10 TD index $=80 \%$ ). A non-dose-dependent presence of preimplantation fetal death was found. The percentage of preimplantation fetal death in female rats receiving the drug in doses corresponding to TD and 10 TD, mated with intact males, was 15.4 and $7.1 \%$, respectively, and differed from control animals, in which it was $0 \%$. Dose-dependent post-implantation fetal death was established in female rats treated with the drug in TD and 10 TD, mated with intact males. The percentage of post-implantation fetal death in female rats receiving the drug in TD and 10 TD doses, mated with intact males, was 18.2 and $24.6 \%$, respectively, which exceeded the percentage of post-implantation fetal death in control animals by 4-5.5 times. During external examination of live fetuses, there were no visible abnormalities of fetal development. Fetuses' weight and craniocaudal size did not differ from the data in control groups ( $\triangleright$ Table 2 ).

In the study of physical development of offspring born by female rats receiving Lipophtalocyan in total doses corresponding to TD and 10 TD mated with intact males, and from intact female rats mated with males receiving Lipophtalocyan in the same doses, the 
- Table 1 Results of the study of reproductive toxicity of non-inbred male rats, after the use of Lipophtalocyan, mated with intact female rats.

\begin{tabular}{|c|c|c|c|c|}
\hline \multirow[t]{2}{*}{ Indicators } & \multicolumn{4}{|c|}{ Male rats } \\
\hline & $\Sigma$ dose TD & $\Sigma$ dose 10 TD & $0.9 \% \mathrm{NaCl}$ & Intact control \\
\hline Total number of dissected female rats & 20 & 20 & 20 & 20 \\
\hline Number of pregnant female rats & 12 & 4 & 20 & 19 \\
\hline Index of the ability to fertilize and conceive (\%) & 60 & 20 & 100 & 95 \\
\hline The number of live fetuses $* *$ & 10.8 & 7.5 & 10.7 & 11.9 \\
\hline Number of resorptions & 2 & 3 & 0 & 1 \\
\hline Number of yellow bodies in the ovaries * * & 11.5 & 9.0 & 8.6 & 12.3 \\
\hline Number of implantationsites $* *$ & 11.0 & 9.0 & 11.0 & 12.5 \\
\hline The number of dead fetuses & 0 & 0 & 0 & 0 \\
\hline Preimplantation death (\%) & 4.3 & 0 & 0 & 0 \\
\hline Post-implantation death (\%) & 1.8 & 16.7 & 2.7 & 4.8 \\
\hline Average fetus weight at opening $(\mathrm{g})$ & $6.1 \pm 1.9^{*}$ & $6.5 \pm 1.9^{*}$ & $6.8 \pm 1.3^{*}$ & $7.1 \pm 1.2$ \\
\hline Craniocaudal size $(\mathrm{mm})$ & $37.0 \pm 8.9^{*}$ & $39.0 \pm 7.1^{*}$ & $39.0 \pm 6.9^{*}$ & $40.0 \pm 5.9$ \\
\hline
\end{tabular}

- Table 2 Results of the study of reproductive toxicity of non-inbred female rats, after the use of Lipophtalocyan, mated with intact male rats.

\begin{tabular}{|c|c|c|c|c|}
\hline \multirow[t]{2}{*}{ Indicators } & \multicolumn{4}{|c|}{ Female rats } \\
\hline & $\Sigma$ dose TD & $\Sigma$ dose 10 TD & $0.9 \% \mathrm{NaCl}$ & Intact control \\
\hline Total number of dissected female rats & 20 & 20 & 20 & 20 \\
\hline Number of pregnant female rats & 1 & 16 & 20 & 19 \\
\hline $\begin{array}{l}\text { Index of the ability to fertilize and conceive } \\
\text { (\%) }\end{array}$ & 5 & 80 & 100 & 95 \\
\hline The number of live fetuses $* *$ & 9 & 9.8 & 10.6 & 11.9 \\
\hline Number of resorptions & 2 & 28 & 1 & 1 \\
\hline Number of yellow bodies in the ovaries $* *$ & 13 & 14.0 & 10.3 & 12.3 \\
\hline Number of implantationsites $* *$ & 11 & 13.0 & 11.1 & 12.5 \\
\hline The number of dead fetuses & 0 & 0 & 3 & 0 \\
\hline Preimplantation death (\%) & 15.4 & 7.1 & 0 & 0 \\
\hline Post-implantation death (\%) & 18.2 & 24.6 & 4.5 & 4.8 \\
\hline Average fetus weight at opening $(\mathrm{g})$ & $5.3 \pm 1.7^{*}$ & $5.6 \pm 1.8^{*}$ & $6.6 \pm 1.3^{*}$ & $7.1 \pm 1.2$ \\
\hline Craniocaudal size $(\mathrm{mm})$ & $38.0 \pm 8.9^{*}$ & $39.0 \pm 10.0^{*}$ & $40.0 \pm 9.7^{*}$ & $40.0 \pm 5.9$ \\
\hline
\end{tabular}

predominance of male offspring in comparison with the offspring of control animals was discovered.

When studying the physical development of offspring born from female rats receiving Lipophtalocyan in total doses corresponding to TD and 10 TD mated with intact males, and from intact female rats mated with males receiving Lipophtalocyan in the same doses, a statistically unreliable lag in the physiological increase in body weight of the offspring was found in comparison with control animals ( $\triangleright$ Table 3 ).

There was a slight delay in the teething of incisors (14-16 days) and eye opening (15-18 days) in offspring born from female rats receiving Lipophtalocyan in total doses corresponding to TD and 10 TD mated with intact males, and from intact female rats mated with males receiving Lipophtalocyan in the same doses compared to the development of offspring of control animals (6-12 days and 13-14 days, respectively) ( $\vee$ Tables 4 and $\triangleright \mathbf{5}$ ).
During the period of feeding this offspring, sensory-motor reflexes were without features and did not differ from the reflexes of the offspring of control animals.

During the pathoanatomic study of unborn fetuses at the end of the antenatal period of development, the absence of abnormalities of external development, development of the bone system, brain and internal organs was found ( $\triangleright$ Tables 6,7 ).

When studying the embryotoxic and teratogenic effects of Lipophtalocyan in female rats receiving the drug in TD and 10 TD mated with intact males and in intact female rats mated with males receiving the drug in the same doses, the number of live fetuses was almost the same and did not differ from the indicators of control animals. During external examination of the fetuses of experimental and control groups under binoculars, no external malformations or abnormalities were detected. In intact female rats mated with males who received the drug in the studied doses, and in female rats who received the drug in the corresponding doses, 
- Table 3 The change in body weight of offspring born from non-inbred rats after administration of Lipophtalocyan.

\begin{tabular}{|l|l|l|l|l|l|l|}
\hline \multirow{2}{*}{ Sex } & \multirow{2}{*}{$\boldsymbol{\Sigma}$ dose } & \multicolumn{5}{|c|}{ Day of experience } \\
\cline { 3 - 7 } & & $\mathbf{7}$ & $\mathbf{1 4}$ & $\mathbf{2 1}$ & $\mathbf{2 8}$ & $\mathbf{3 5}$ \\
\hline Female & TD & $13.5 \pm 1.5^{*}$ & $36.3 \pm 3.8^{*}$ & $36.3 \pm 3.8^{*}$ & $61.4 \pm 5.3^{*}$ & $108.7 \pm 7.4^{*}$ \\
\hline & $10 \mathrm{TD}$ & $11.2 \pm 2.0^{*}$ & $31.5 \pm 4.2^{*}$ & $31.5 \pm 4.2^{*}$ & $64.0 \pm 6.0^{*}$ & $116.5 \pm 8.7^{*}$ \\
\hline Male & $0.9 \% \mathrm{NaCl}$ & $16.0 \pm 3.2^{*}$ & $42.7 \pm 3.5^{*}$ & $42.7 \pm 3.5^{*}$ & $72.1 \pm 5.8^{*}$ & $129.5 \pm 8.2^{*}$ \\
\hline & $\mathrm{TD}$ & $12.5 \pm 2.5^{*}$ & $31.0 \pm 5.0^{*}$ & $31.0 \pm 5.0^{*}$ & $52.9 \pm 4.7^{*}$ & $103.2 \pm 18.9^{*}$ \\
\hline & $10 \mathrm{TD}$ & $14.0 \pm 1.9^{*}$ & $40.6 \pm 4.7^{*}$ & $40.6 \pm 4.7^{*}$ & $61.2 \pm 5.1^{*}$ & $102.7 \pm 12.3^{*}$ \\
\hline Intactcontrol & $0.9 \% \mathrm{NaCl}$ & $15.3 \pm 2.1^{*}$ & $39.9 \pm 3.9^{*}$ & $39.9 \pm 3.9^{*}$ & $65.9 \pm 4.8^{*}$ & $118.2 \pm 9.1^{*}$ \\
\hline$*-\mathrm{p}<0.05$ in relation to control. & $15.8 \pm 3.1$ & $26.8 \pm 4.0$ & $35.7 \pm 4.2$ & $67.3 \pm 5.2$ & $124.8 \pm 8.9$ \\
\hline
\end{tabular}

- Table 4 The results of monitoring the physical development of the offspring born from non-inbred female rats after administration of Lipophtalocyan.

\begin{tabular}{|c|c|c|c|c|}
\hline \multirow[t]{2}{*}{ Indicators } & \multicolumn{3}{|c|}{ Female rats } & \multirow[t]{2}{*}{ Intact control } \\
\hline & $\Sigma$ dose TD & $\Sigma$ dose 10 TD & $0.9 \% \mathrm{NaCl}$ & \\
\hline Total number of newborns & 100 & 120 & 100 & 114 \\
\hline The number of dead fetuses & 0 & 10 & 30 & 0 \\
\hline Death index (\%) & 0 & 8.3 & 30 & 0 \\
\hline The number of deaths of newborns & 0 & 30 & 25 & 26 \\
\hline Days of death of newborns (day) & - & $1-2$ & $1-2$ & $2-3$ \\
\hline \multicolumn{5}{|l|}{ Number of rats of different sexes } \\
\hline male & 79 & 70 & 20 & 42 \\
\hline female & 21 & 10 & 25 & 46 \\
\hline Peeling of ear (day) & $2-4$ & $2-4$ & $2-4$ & $2-4$ \\
\hline The appearance of primary hair (day) & $4-5$ & $4-5$ & $4-5$ & $4-5$ \\
\hline The teething of incisors (one day) & $13-14$ & $15-16$ & $6-12$ & $6-12$ \\
\hline Eye opening (day) & $16-17$ & $15-16$ & $13-14$ & $13-14$ \\
\hline Ptosis of testes (day) & $24-26$ & $24-26$ & $24-25$ & $23-25$ \\
\hline Opening of vagina (day) & $27-29$ & $28-30$ & $27-29$ & $28-30$ \\
\hline Average body weight of rat'snewborns for 35 days $(\mathrm{g})$ & $108.7 \pm 7.4^{*}$ & $116.5 \pm 8.7^{*}$ & $129.5 \pm 8.2^{*}$ & $124.8 \pm 8.9$ \\
\hline
\end{tabular}

Table 5 The results of monitoring the physical development of the offspring born from non-inbred male rats after administration of Lipophtalocyan.

\begin{tabular}{|c|c|c|c|c|}
\hline \multirow[t]{2}{*}{ Indicators } & \multicolumn{3}{|c|}{ Male rats } & \multirow[t]{2}{*}{ Intact control } \\
\hline & $\Sigma$ dose TD & $\Sigma$ dose 10 TD & $0.9 \% \mathrm{NaCl}$ & \\
\hline Total number of newborns & 70 & 105 & 110 & 114 \\
\hline The number of dead fetuses & 0 & 0 & 18 & 0 \\
\hline Death index (\%) & 0 & 0 & 16 & 0 \\
\hline The number of deaths of newborns & 1 & 0 & 10 & 26 \\
\hline Days of death of newborns (day) & 9 & - & $2-3$ & $2-3$ \\
\hline \multicolumn{5}{|l|}{ Number of rats of different sexes } \\
\hline male & 52 & 90 & 45 & 42 \\
\hline female & 17 & 15 & 37 & 46 \\
\hline Peeling of ear (day) & $2-4$ & $2-4$ & $2-4$ & $2-4$ \\
\hline The appearance of primary hair (day) & $4-5$ & $4-5$ & $4-5$ & $4-5$ \\
\hline The teething of incisors (one day) & $14-16$ & $14-16$ & $6-12$ & $6-12$ \\
\hline Eye opening (day) & $17-18$ & $17-18$ & $13-14$ & $13-14$ \\
\hline Ptosis of testes (day) & $24-26$ & $24-26$ & $24-25$ & $23-25$ \\
\hline Opening of vagina (day) & $28-30$ & $27-29$ & $28-30$ & $28-30$ \\
\hline Average body weight of rat's newborns for 35 days $(\mathrm{g}$ ) & $103.2 \pm 18.9^{*}$ & $102.7 \pm 12.3^{*}$ & $118.2 \pm 9.1^{*}$ & $124.8 \pm 8.9^{*}$ \\
\hline
\end{tabular}


\ Table 6 The results of postmortem studies of fetuses for teratogenic effects received from non-inbred male rats, after administration of Lipophtalocyan.

\begin{tabular}{|c|c|c|c|c|c|}
\hline \multicolumn{2}{|l|}{ Indicators } & \multicolumn{3}{|c|}{ Male rats } & \multirow[t]{2}{*}{ Intact control } \\
\hline & & $\Sigma$ dose TD & $\Sigma$ dose 10 TD & $0.9 \% \mathrm{NaCl}$ & \\
\hline \multicolumn{6}{|l|}{ External inspection of fetuses } \\
\hline Number of examined fetuses & & 130 & 30 & 214 & 238 \\
\hline \multirow{2}{*}{$\begin{array}{l}\text { Number of fetuses with developmental } \\
\text { abnormalities }\end{array}$} & abs. & 0 & 0 & 0 & 0 \\
\hline & $\%$ & 0 & 0 & 0 & 0 \\
\hline \multicolumn{6}{|l|}{ State of the bone system } \\
\hline Number of examined fetuses & & 65 & 15 & 107 & 119 \\
\hline \multirow{2}{*}{$\begin{array}{l}\text { Number of fetuses with developmental } \\
\text { abnormalities }\end{array}$} & abs. & 0 & 0 & 0 & 0 \\
\hline & $\%$ & 0 & 0 & 0 & 0 \\
\hline \multicolumn{6}{|l|}{ State of internal organs } \\
\hline Number of examined fetuses & & 65 & 15 & 107 & 119 \\
\hline \multirow{2}{*}{$\begin{array}{l}\text { Number of fetuses with developmental } \\
\text { abnormalities }\end{array}$} & abs. & 0 & 0 & 0 & 0 \\
\hline & $\%$ & 0 & 0 & 0 & 0 \\
\hline
\end{tabular}

- Table 7 The results of postmortem studies of fetuses for teratogenic effects received from non-inbred female rats, after administration of Lipophtalocyan.

\begin{tabular}{|c|c|c|c|c|c|}
\hline \multicolumn{2}{|l|}{ Indicators } & \multicolumn{3}{|c|}{ Female rats } & \multirow[t]{2}{*}{ Intact contro } \\
\hline & & $\Sigma$ dose TD & $\Sigma$ dose 10 TD & $0.9 \% \mathrm{NaCl}$ & \\
\hline \multicolumn{6}{|l|}{ External inspection of fetuses } \\
\hline Number of examined fetuses & & 9 & 157 & 212 & 238 \\
\hline \multirow{2}{*}{$\begin{array}{l}\text { Number of fetuses with developmental } \\
\text { abnormalities }\end{array}$} & abs. & 0 & 0 & 0 & 0 \\
\hline & $\%$ & 0 & 0 & 0 & 0 \\
\hline \multicolumn{6}{|l|}{ State of the bone system } \\
\hline Number of examined fetuses & & 4 & 77 & 106 & 119 \\
\hline \multirow{2}{*}{$\begin{array}{l}\text { Number of fetuses with developmental } \\
\text { abnormalities }\end{array}$} & abs. & 0 & 0 & 0 & 0 \\
\hline & $\%$ & 0 & 0 & 0 & 0 \\
\hline \multicolumn{6}{|l|}{ State of internal organs } \\
\hline Number of examined fetuses & & 5 & 80 & 106 & 119 \\
\hline \multirow{2}{*}{$\begin{array}{l}\text { Number of fetuses with developmental } \\
\text { abnormalities }\end{array}$} & abs. & 0 & 0 & 0 & 0 \\
\hline & $\%$ & 0 & 0 & 0 & 0 \\
\hline
\end{tabular}

mated with intact males, the number of dead fetuses was not found, which did not differ from the indicators of control animals ( Tables 8,9).

After application of Lipophtalocyan in female rats at a total dose corresponding to 10 TD and mated with intact males, an increase in the number of fetus resorption was observed by $\approx 30$ times in contrast to control animals. In intact female rats mated with males who received the drug in TD and 10 TD and in female rats who received the drug in TD and mated with intact males, fetus resorption was not found, which did not differ from the indicators of control animals ( $\triangleright$ Tables 8,9).

A non-dose-dependent effect of the drug on preimplantation fetal death was observed in female rats treated with Lipophtalocyan in TD and 10 TD mated with intact males. The percentage of preimplantation fetal death in female rats treated with the drug in TD and 10 TD mated with intact males (15.4 and $7.1 \%$, respectively), in contrast to control animals in which preimplantation fetal death was not observed. Preimplantation fetal death was observed only in intact female rats mated by males who received Lipophtalo- cyan at a dose of the corresponding TD. The percentage of preimplantation fetal death in intact female rats mated with males receiving Lipophtalocyan at a dose of the corresponding TD was $4.3 \%$. Preimplantation fetal death in intact female rats mated by males receiving Lipophtalocyan at a dose corresponding to 10 TD was not observed, which corresponded to the indicators of control animals ( $\triangleright$ Tables $\mathbf{8 , 9}$ ).

The dose-dependent effect of the drug on post-implantation fetal death in female rats treated with Lipophtalocyan in TD and 10 TD mated with intact males was noted. In intact female rats mated with males receiving Lipophtalocyan, post-implantation fetal death was observed only at a dose corresponding to 10 TD. Post-implantation fetal death in intact female rats mated with males receiving Lipophtalocyan at a dose of the corresponding TD did not differ from the values of control animals.

There was a high percentage of post-implantation fetal death in female rats treated with the drug in TD and 10 TD, mated with intact males ( 18.2 and $24.6 \%$, respectively, which exceeded by more than $\approx 4-5$ times the percentage of post-implantation fetal 
- Table 8 The results of a study of the embryotoxic action of Lipophtalocyan on non-inbred female rats.

\begin{tabular}{|c|c|c|c|c|}
\hline \multirow[t]{2}{*}{ Indicators } & \multicolumn{3}{|c|}{ Female rats } & \multirow[t]{2}{*}{ Intact contro } \\
\hline & $\Sigma$ dose TD & $\Sigma$ dose 10 TD & $0.9 \% \mathrm{NaCl}$ & \\
\hline Number of pregnant females & 1 & 16 & 20 & 19 \\
\hline Number of yellow bodies * * & 13.0 & 14.0 & 10.3 & 12.3 \\
\hline Number of implantation sites ${ }^{*} *$ & 11.0 & 13.0 & 11.1 & 12.5 \\
\hline The number of live fetuses $* *$ & 9.0 & 9.8 & 10.6 & 11.9 \\
\hline Number of resorptions & 2 & 28 & 1 & 1 \\
\hline The number of dead fetuses & 0 & 0 & 0 & 0 \\
\hline Preimplantation death (\%) & 15.4 & 7.1 & 0 & 0 \\
\hline Post-implantation death (\%) & 18.2 & 24.6 & 4.5 & 4.8 \\
\hline Average fetus weight atautopsy $(\mathrm{g})$ & $5.3 \pm 1.7^{*}$ & $5.6 \pm 1.8^{*}$ & $6.6 \pm 1.3^{*}$ & $7.1 \pm 1.2$ \\
\hline Craniocaudal size $(\mathrm{mm})$ & $38.0 \pm 8.9 *$ & $39.0 \pm 10.0^{*}$ & $40.0 \pm 9.7 *$ & $40.0 \pm 5.9$ \\
\hline
\end{tabular}

- Table 9 The results of a study of the embryotoxic action of Lipophtalocyan on non-inbred male rats.

\begin{tabular}{|c|c|c|c|c|}
\hline \multirow[t]{2}{*}{ Indicators } & \multicolumn{3}{|c|}{ Male rats } & \multirow[t]{2}{*}{ Intact control } \\
\hline & $\Sigma$ dose TD & $\Sigma$ dose 10 TD & $0.9 \% \mathrm{NaCl}$ & \\
\hline Number of pregnant females & 12 & 4 & 20 & 19 \\
\hline Number of yellow bodies * * & 11.5 & 9.0 & 8.6 & 12.3 \\
\hline Number of implantation sites $* *$ & 11.0 & 9.0 & 11.0 & 12.5 \\
\hline The number of live fetuses * * & 10.8 & 7.5 & 10.7 & 11.9 \\
\hline Number of resorptions & 2 & 3 & 0 & 1 \\
\hline The number of dead fetuses & 0 & 0 & 0 & 0 \\
\hline Preimplantation death (\%) & 4.3 & 0 & 0 & 0 \\
\hline Post-implantation death (\%) & 1.8 & 16.7 & 2.7 & 4.8 \\
\hline Average fetus weight at autopsy $(\mathrm{g})$ & $6.1 \pm 1.9^{*}$ & $6.5 \pm 1.9^{*}$ & $6.8 \pm 1.3^{*}$ & $7.1 \pm 1.2$ \\
\hline Craniocaudal size (mm) & $37.0 \pm 8.9^{*}$ & $39.0 \pm 7.1^{*}$ & $39.0 \pm 6.9$ & $40.0 \pm 5.9$ \\
\hline
\end{tabular}

death in control animal groups). The percentage of post-implantation fetal death in intact female rats paired with males receiving Lipophtalocyan at a dose corresponding to 10 TD was $16.7 \%$, which exceeded by $\approx 3$ times the percentage of post-implantation fetal death in control animal groups ( $\triangleright$ Tables 8,9 ).

\section{Conclusion}

Lipophthalocyan negatively affects the reproductive function of males based on the criteria for assessing male fertility, causing a dose-dependent decrease in the fertilizing ability, affecting females' ability to conceive and causing post-implantation death of fetuses (index of the ability to fertilize and conceive 60 and $20 \%$ and post-implantation death of fetuses 1.8 and $16.7 \%$ respectively).

Lipophthalocyan negatively affects the reproductive function of females (based on the criteria for assessing female fertility), causing an overall (not dose-dependent) decrease in the ability to fertilize, conceive and resulting in post-implantation death of fetuses (index of the ability to fertilize and conceive 5 and $80 \%$ and postimplantation death of fetuses 18.4 and $24,6 \%$ respectively).
Lipophthalocyan has an embryotoxic effect (based on the criteria for the presence of fetal resorption, pre- and post-implantation fetal death). Female rats administered with the drug in a total dose corresponding to 10 TD and paired with intact males had a 30times increase in the number of fetal resorptions compared to control animals. Intact female rats mated with males receiving the drug in TD and 10 TD, and female rats receiving the drug in TD and mated with intact males, did not have fetal resorptions just like the control animals.

Daily i.v. administrations of Lipophthalocyan to male and female rats in total doses corresponding to TD and 10 TD, resulted in pre-implantation fetal deaths that were not dose-dependent. When intact female rats mated with males receiving Lipophthalocyan in a dose corresponding to TD the increase in preimplantation death of embryos was detected (the percentage of preimplantation embryo death was $4.3 \%$ ). Interestingly, preimplantation death of embryos was not observed in intact female rats mated with males with drug exposure at a total dose of 10 TD.

The percentage of preimplantation death of embryos in female rats treated with Lipophthalocyan in doses corresponding to TD and 10 TD, and mated with intact males, was 15.4 and $7.1 \%$, respectively. 
Lipophthalocyan caused post-implantation fetal death in intact females fertilized by male rats, exposed to Lipophthalocyan in a total dose corresponding to 10 TD (the percentage of post-implantation fetal death was $16.7 \%$, which was $4.5-6$ times higher than in control animals). When intact female rats were mated with males receiving Lipophthalocyan in a dose corresponding to TD, the percentage of post-implantation fetal death did not differ from control animals (1.8\%).

In female rats, receiving the drug in total doses corresponding to TD and 10 TD and mated with intact males, the percentage of post-implantation fetal death was 18.2 and $24.6 \%$, respectively, which was 4-5.5 times higher than in control animals.

The physical development of offspring born from intact females and Lipophthalocyan-exposed male rats (total doses corresponding to TD and 10 TD), as well as from intact males mated with female rats receiving Lipophthalocyanine in the total doses corresponding to TD and 10 TD, pdid not differ from the physical development of the offspring of control animals.

The maturation rate of sensory-motor reflexes during the period of suckling in the offspring born from intact females mated with male rats receiving Lipophthalocyan in total doses corresponding to TD and 10 TD, and from intact males mated with female rats receiving Lipophthalocyan doses in total corresponding TD and 10 TD did not differ from the rate of maturation of sensory-motor reflexes of the offspring of control animals.

Lipophtalocyan has a damaging effect on the reproductive function of males and females rats and intrauterine development of fetuses (embryotoxicity) of non-harmless rats according to the index of the ability to fertilize and conceive, and according to the indices of preimplantation and post-implantation death of fetuses. The damaging effect on the reproductive function and intrauterine development of fetuses (embryotoxicity) is more pronounced in female ratswho received the drug and mated with intact male rats than in intact female rats mated with male rats who received the drug.

The drug does not cause fetal death, teratogenic effect, does not affect the physical development of offspring and the rate of maturation of sensory-motor reflexes during the period of feeding offspring.

\section{Conflict of Interest}

The authors declare no conflict of interest.
[3] Meerovich GA, Borisova LM, Bud'Ko AP et al. Study of level and selectivity of liposomal form of photosensitiser hydroxyaluminium tetra-3-phenylthiophthalocyanine accumulation on transplantable mice tumor models at different ways of transplantation. Russ J Biother 2017; 16: 74-79. doi:10.17650/1726-9784-2017-16-4-74-79

[4] Budko AP, Deichman ZG, Meerovich GA et al. Study of pharmacokinetics of liposomal photosensitiser based on hydroxyaluminium tetra-3-phenylthiophthalocyanine on mice. Biomedical Photonics 2018; 4: 16-22. doi:10.24931/2413-9432-2018-7-4-16-22

[5] Meerovich I, Nichols MG, Dash AK. Low-intensity light-induced paclitaxel release from lipid-based nano-delivery systems. J Drug Targeting 2019; 27: 971-983. doi:10.1080/1061186X.2019.1571066

[6] Koshkaryev A, Thekkedath R, Pagano C et al. Intracellular Targeting of Lysosomes by Liposomes Modified with Octadecyl-Rhodamine B. J Drug Targeting 2011; 19: 606-614. doi:10.3109/106118 6X.2010.550921

[7] Smol'nikova NM, Chirkova EM, Golovanova IV et al. Guidelines for the preclinical study of the reproductive toxicity of pharmacological agents. Vedomosti Farmakologicheskogo Komiteta 1998; 1: 13-20

[8] Smolnikova NM, Lyubimov BI, Durnev AD et al. Methodical recommendations for study of reproductive toxicity of pharmacological substances. In: Khabriev RU (Ed).Guidance on the experimental (preclinical) study of new pharmacological substances. Moscow: Medicine; 2005: $87-100$

[9] Durnev AD, Smolnikova NM, Skosyreva AM et al. Methodical recommendations for the study of reproductive toxicity of drugs. In: Mironov AN (ed). Preclinical Drug Research Guide, part 1. Moscow: Grif \& K; 2012: 80-93

[10] Bol'shakov OP, Neznanov NG, Babakhanyan RV. Didactic and ethical aspects of research on biomodels and laboratory animals. Kachestvennaya klinicheskaya praktika 2002; 1: 58-61https://www.clinvest.ru/ jour/article/view/249\#tab1

[11] Freireich EJ, Gehan EA, Rall DP et al. Quantitative comparison of toxicity of anticancer agents in mouse, rat, hamster, dog, monkey, and man. Cancer Chemother Rep 1966; 50: 219-244

[1] Meerovich IG, Sanarova EV, Meerovich GA et al. Near-infrared photosensitizers based on nanostructured forms of phthalocyanine derivatives. Russ J General Chem 2015; 85: 280-288. doi:10.1134/ S1070363215010430

[2] Sanarova EV, Lantsova AV, Polozkova AP et al. Effectiveness of liposomal system of delivery of hydrophobic antineoplastic thiosens photosensitizer. Nanotechnologies in Russ 2015; 10: 492-500. doi:10.1134/S1995078015030143 